\title{
A ETNOGRAFIA RÁPIDA NO \\ METAPROJETO DE DESIGN PARA O \\ TERRITÓRIO
}

\section{RAPID ETHNOGRAPHY IN METAPROJECT OF DESIGN TO TERRITORY}

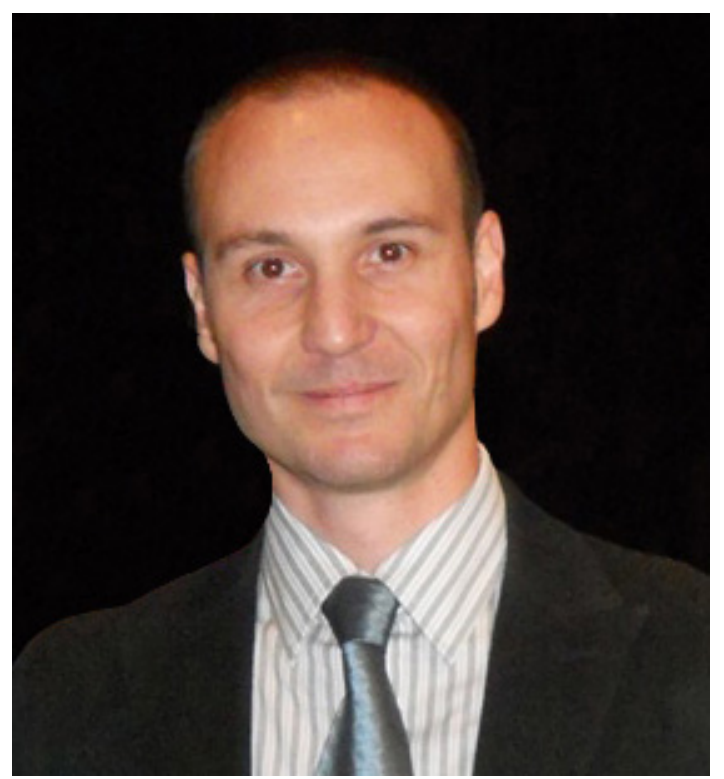

\author{
André de Souza Lucca \\ Doutor em Ciências do Design, Università luav di \\ Venezia - Itália \\ Programa de Pós-graduação em Design, Universi- \\ dade Federal do Maranhão \\ aslucca@yahoo.com.br
}

\section{RESUMO}

Baseado em uma revisão bibliográfica, o presente texto apresenta as relações entre a etnografia rápida e o metaprojeto de design para o território. O objetivo deste estudo é fornecer uma contribuição para a área de pesquisa e desenvolvimento de produtos e serviços locais, integrando os saberes do design com a etnografia e auxiliando na compreensão do papel da participação no desenvolvimento do território. Este trabalho se baseia na premissa de que a fase metaprojetual de design pode ser destinada para a formulação de uma diagnose local, que a obtenção de feedback que forneça segurança sobre os resultados obtidos pode ser facilitada com o envolvimento dos atores locais no processo projetual e que a etnografia pode fornecer ferramentas para produção de conhecimentos baseados 
na observação em campo. Este estudo permitiu inferir que as ferramentas baseadas na etnografia rápida permitem focalizar as relações entre 0 ambiente, as pessoas e os artefatos com o objetivo de compreender, descrever e explicar as relações, as criticidades e as convenções nas quais se fundam as ações sociais de grupos, organizações e comunidades, que o envolvimento dos atores locais e a observação participativa são indispensáveis para a construção dos objetivos e requisitos do projeto pois permitem a coleta de informações diretamente do contexto e a inserção dos conhecimentos locais no processo criativo de design.

\section{PALAVRAS-CHAVE}

Design para o território. Observação participativa. Diagnose local.

\section{ABSTRACT}

Based on a bibliographic review, this paper presents the relationships between rapid ethnography and the metaproject of design to territory. With this study we intend to provide an contribution to research and development area of local products and services that integrate the design knowledge with ethnography and help us to understand the role of participation in regional development. This work is based on the premise that the metaprojetual stage of a design can be used in the formulation of a diagnosis, so that the achievement of a feedback gives security to the results obtained can be facilitated with the involvement of local actors in projectual process, and so that the ethnography can provide tools for the production of knowledge based on field observation. This study led us to infer that the tools based on rapid ethnography allow focus on the relations between the environment, people and artifacts. The primary objective is to understand, describe and explain the relationships, critical thinking and conventions in which the social actions of groups, their organizations and their communities are founded. But we also want to confirm that the involvement of local actors and the participant observation are essential to build objectives and requirements of the project, since they are the ones that allow to collect information directly from the context and to insert the local knowledge into the creative process of design. 


\section{KEYWORDS}

Design to territory. Participant observation. Local diagnosis.

\section{INTRODUÇÃO}

O projeto como sequência de decisões depende da coleta das informações que representam o conhecimento útil para a análise e a fundamentação das decisões. Nesse sentido, quando se toma uma decisão de projeto, se procede com uma seleção entre diferentes alternativas. Para garantir que essas determinações tenham uma base sólida, recolhese muitos dados. Para Bonsiepe (1978, p. 25), a fase de coleta dos dados em um projeto apresenta alguns problemas, o designer pode facilmente transformar-se num burocrata da documentação e se desorientar de seu objetivo de projeto. Para projetar de forma mais apurada, o designer tem a necessidade de obter informações úteis e relevantes que o auxiliem no processo decisório e no decorrer de suas ações projetuais.

Como elemento determinante da fase de estruturação do problema de projeto, o metaprojeto se configura como o período da coleta das informações relacionadas aos objetivos que se pretende alcançar, aos meios que se tem a dispor e às condições específicas do contexto que se deseja intervir. Segundo Deserti (2003, p. 18), é o momento da definição dos vínculos do projeto, que nasce da consideração das exigências de uma pluralidade de sujeitos que devem ser considerados como referência para o próprio projeto, seja no caso em que tais sujeitos resultem parte ativa no projeto ou que façam parte só idealmente.

Para Collina (2005, p. 22), o metaprojeto é o período que se coloca como gerador de múltiplas soluções para o inteiro processo ideativo. Nas fases propositivas, dando origem as hipóteses de projeto. Na fase de desenvolvimento das soluções, auxiliando na compreensão dos princípios e tecnologias envolvidas, transformando, hibridando e organizando, na forma de sistema, as soluções existentes. Na fase de seleção da solução, ajudando a entender o contexto em que estão inseridos os clientes, os usuários, os aspectos normativos e produtivos. $E$, também, fornecendo uma base para $O$ processo de falsificação das hipóteses de projeto propostas.

De acordo com Deserti (2003, p. 19), as atividades de projeto foram historicamente interpretadas a partir de três diferentes abordagens. $O$ 
projeto como a capacidade de definição das características de performance frente a identificação preliminar dos requisitos. O projeto como a evolução de uma solução tipo ou como a combinação de elementos ao interno de um sistema definido por regras. E o projeto como o governo de um processo, cuja a qualidade se transforma na capacidade de transformar o processo não casual, mas guiado por regras e transformado em procedimentos repetíveis, ou seja, num método.

A partir dessas três concepções de projeto, Deserti (2003, p. 20) distende as três possíveis definições para o metaprojeto. $O$ metaprojeto como a construção do sistema de necessidades, dos vínculos e das variáveis que determinam o projeto e das ferramentas para monitorar o cumprimento dessas restrições. O metaprojeto como o projeto tipológico, que se realiza normalmente por sistemas e componentes a partir da ideia de que isso seja o gerador de mais projetos possíveis. E o metaprojeto como o método, isto é, como projeto do processo e de suas regras.

Por isso, conforme Collina (2005, p. 39), o metaprojeto pode se declinar em diversos papéis. Como atividade geradora de sucessivas operações de projeto que, de diferentes maneiras, propõe vínculos ou expressa as diretrizes para as ações projetuais que seguem. Como produto de uma ação projetual finalizada para a coleta de informações, sua aplicação no caso específico e tradução em forma inteligível (requisitos e prestações) daqueles vínculos, prescrições, indicações ou orientações. Como informações complexas relativas aos objetivos perseguidos (definidos com base nas expectativas dos usuários, nas funções e nos campos tecnológicos), aos meios à disposição e ao contexto de referência. E como ferramenta para a verificação dos resultados no que diz respeito as funções institucionalmente a eles atribuídos.

Ainda segundo Collina (2005, p. 66), o metaprojeto pode assumir, além disso, o papel de plataforma de comunicação, compartilhando as informações entre atores provenientes de diferentes disciplinas do projeto, mas não só, também entre diferentes figuras empreendedoras até compreender os próprios destinatários do projeto.

\section{O META PROJETO NO DESIGN}

Focalizando o trabalho sobre cenários muito amplos, o metaprojeto na ótica do design não se concentra em um único artefato, mas sim, sobre o sistema. Na visão de Collina (2005, p. 68-69), o metaprojeto é um modo 
projetual que leva a criação de visões, estratégias e cenários de inteiros sistemas e famílias de produtos, planos estéticos globais capazes de coordenar linhas de diferentes produtos ou programas de estilos formais que orientam os designers no desenvolvimento das sucessivas séries e variantes do produto. Leva também a elaboração não mais de propostas operacionais, mas sim, de geratrizes capazes de ativar percursos e matrizes de inovação que abrem um leque de possíveis trajetórias projetuais.

Um outro aspecto característico do metaprojeto é dado pelo seu grau de inovação. Segundo Migliari (apud Collina, 2005, p. 70), na atividade de design muitas vezes o campo de ação é delimitado por um brief e por um comportamento tipológico, de tal forma que o design assume a aparência de um mero re-design. Para o autor, o metaprojeto, ao contrário, tem o escopo de constituir e formular uma questão cuja a resposta ainda não foi formulada. Deste ponto de vista, o metaprojeto no design visa uma inovação radical não enquadrada pela presença de um brief já definido, não vinculada pelas tipologias de produtos e serviços existentes ou por comportamentos de uso estabelecidos.

Para Collina (2005, p. 71), a partir desse ponto de vista, o metaprojeto no design passa a ser uma ferramenta ativa de modificação comportamental que pode determinar um novo código de uso do objeto e que, por sua vez, também pode estabelecer novas funções.

Segundo De Moraes (2010):

O modelo metaprojetual se consolida, portanto, pela formatação e prospecção teórica que precede a fase projetual ao elaborar um ou mais cenários por meio de novas propostas conceituais (concept), destinadas a um novo produto ou serviço, ou a efetuação de análises corretivas (diagnose) em produtos e/ou serviços já existentes. A diferença, portanto, nesse modelo projetual é que o design se apresenta como sendo muito mais que o projeto da forma do produto, alargando o seu raio de ação junto ao complexo conjunto de atividade que compreendem um projeto do início ao fim. A forma e as funções que compreendem o produto passam a ser o nosso ponto de partida e não o fim do projeto. Os designers, por sua vez, passam a trabalhar com a possibilidade de cenários, em vez de atuar de forma pontual na busca de resolver o problema de cada fase linear do processo metodológico. Nesse sentido, a ação de conhecimento e de análise prévia da realidade existente (cenário atual) ou prospectada (cenário futuro) faz plenamente parte do processo de design (DE MORAES, 2010, p. 21).

Portanto, em propostas de design para o desenvolvimento do território é possível considerar a fase metaprojetual como o momento destinado 
para a formulação da diagnose local. Uma vez que, em projetos orientados para o desenvolvimento regional, é indispensável a obtenção de feedback que assegure as escolhas e garanta um certo grau de segurança sobre os resultados finais do projeto, a participação dos atores (usuários, fruidores, operadores e decisores) ou de suas representações, deve ser um processo que acompanha a evolução de todo o processo projetual. O envolvimento dos decisores (públicos e privados), por exemplo, tem tanto uma finalidade de sensibilização quanto de participação ativa no projeto, começando pela própria definição das propostas de intervenção. Nesse contexto, o designer pode assumir o papel de coordenador não somente das fases tipicamente de design e de controle da execução do projeto, mas de todas as etapas, compreendendo, inclusive, aquelas precedentes ao design brief e posteriores a realização dos produtos e serviços.

Para formular uma diagnose é, antes de tudo, necessário identificar os problemas e as oportunidades presentes no território em que se vai trabalhar. De acordo com o Observatório Europeu Leader (1996b), para fazer isso, podem ser efetuados estudos de benefícios e obstáculos, fixados os objetivos, identificadas as prioridades e as modalidades de ação. Quando se inicia um projeto de desenvolvimento local, a prioridade é representada pela elaboração de uma visão do conjunto do território, seja para permitir a população o sentimento de estar diretamente envolvida e participante, mas também para começar a identificar novas oportunidades. Inicialmente, a ideia de iniciar um projeto local geralmente ocorre a partir de um pequeno grupo de pessoas. Na maior parte dos casos esse grupo é muito homogêneo. É, por exemplo, composto por empreendedores de um mesmo setor profissional, de representantes locais que compartilham uma mesma análise sobre o futuro da área ou de uma associação que intervém geralmente sobre um tema específico. O primeiro objetivo a se alcançar será a ampliação e a diversificação da problemática inicial e da composição do grupo de base. Esse duplo objetivo pode ser alcançado atuando uma primeira diagnose dirigida para uma melhor compreensão e conhecimento da totalidade do território.

\section{A PARTICIPAÇÃO NO DESENVOLVIMENTO DO TERRITÓRIO}

No decorrer dos últimos anos, afirmou-se a importância da participação 
da população nos projetos de valorização do território. De acordo com o Observatório Europeu Leader (1996a), tal situação satisfaz três principais necessidades:

a) Empregar melhor os conhecimentos, as competências, as dinâmicas e os recursos existentes em nível local;

b) Obter a adesão e o empenho dos atores e operadores locais no confronto dos problemas fundamentais e identificar as possíveis soluções;

c) Favorecer a apropriação local dos projetos, de forma a assegurar a sua continuidade.

Contudo, a efetiva participação da população depende de múltiplos fatores, como os níveis de intervenção, os recursos disponíveis, as condições políticas, econômicas, sociais e culturais. Com base nas indicações do Observatório Europeu Leader (1996a), sugere-se que, na prática, a participação do público em projetos de design para o território pode se situar em níveis muito diferentes, como:

a) Em consultorias para a análise do mérito das propostas apresentadas, oferecendo informações adequadas e prevendo os meios que permitirão, para cada um, a formulação do próprio parecer;

b) No empenho nas diferentes fases do projeto dos atores e operadores locais mediante a participação nas discussões e nos processos decisórios;

c) No co-design, propriamente dito, dos produtos, serviços e infraestruturas;

d) Na gestão do processo de desenvolvimento direto dos projetos.

Identificadas as razões fundamentais para a participação do público, torna-se essencial determinar se énecessário pôr o foco em grupos específicos da população. A resposta dependerá em grande parte do contexto social e cultural. Nesse sentido, é possível identificar alguns grupos locais com os quais a atividade de design frequentemente se envolve:

a) A comunidade de projetistas: designers, arquitetos, engenheiros, urbanistas, entre outros;

b) Os membros dos grupos de interesse econômico, social e cultural: associações de profissionais, consórcios produtivos, associações comunitárias ou de vizinhança, cooperativas, sindicatos e instituições financeiras;

c) A comunidade acadêmica: pesquisadores, docentes, grupos de pesquisa e estudantes;

d) A representação política e os responsáveis pela administração 
pública.

De acordo com Observatório Europeu Leader (1996a), a participação global e profícua do conjunto da população nos projetos de valorização do território é um objetivo extremamente árduo de se alcançar, quando não utopístico, pois o campo de intervenção seria muito vasto, enquanto que uma população é composta por numerosos grupos sociais com diferentes interesses, preocupações e recursos. De fato, é oportuno identificar o maior número de grupos de interesse que cubram os diferentes aspectos da vida política, econômica, social e cultural, identificar as suas expectativas e motivações, e suscitar neles a participação no processo, focando as suas atenções nas partes e fases do projeto que podem representar, para eles, a maior importância.

Para o Observatório Europeu Leader (1996a), por exemplo, mesmo que a maior parte dos grupos interessados nos resultados do projeto desejem participar nas fases iniciais do planejamento (onde são identificados os problemas e as potencialidades locais) somente alguns grupos, por interesses particulares, se empenharão na criação de novas atividades ou de projetos específicos. "Uma participação construtiva poderá ser suscitada na medida em que se aprecia a pertinência e a importância que os projetos revestem para os grupos interessados".

Ainda para o Observatório Europeu Leader (1996a), o processo de valorização do território terá maiores possibilidades de sucesso quanto mais amplo for a gama de grupos participantes. Os métodos para suscitar a participação da população local em projetos estão estreitamente ligados às diferentes fases do processo. No decorrer de um projeto é possível distinguir quatro fases principais:

a) A fase inicial de sensibilização, informação e motivação: onde se trata de fazer participar todos os atores interessados;

b) A fase de diagnose: que permite a identificação e definição dos problemas existentes;

c) A fase de planejamento e elaboração do projeto: que permite a decisão das ações que serão realizadas;

d) A fase de implementação e acompanhamento: que permitem a execução do projeto e a sua manutenção.

Analisando essas fases, é possível concluir que a primeira fase destinase para orientar o público convocado para participar. Durante esse momento, 
é possível utilizar diversas ferramentas em função dos objetivos pré-fixados, como uma simples consulta, a solicitação de parcerias, as reuniões abertas, as conferências públicas e as mostras itinerantes.

Na segunda fase, ao contrário, são indicados métodos mais seletivos e intensos, como os encontros multidisciplinares, as consultorias com especialistas, as comissões e grupos de trabalho, a organização de associações locais, a elaboração de ferramentas específicas para o diagnóstico local com a população, entre outros.

A fase de elaboração do projeto, que se refere a equipe de design, requer métodos mais especializados e exige ferramentas peculiares do design, como os workshops de design e as avaliações através de consultorias multidisciplinares.

As fases de implementação e de acompanhamento, que se referem diretamente aos grupos interessados pelas ações, requerem também métodos especializados de consultoria, assistência técnica, elaboração de guias de produção, critérios de controle da qualidade e orientações para a manutenção e reparação.

Segundo o Observatório Europeu Leader (1996a), tudo isso demanda notável tempo e energia, envolver a população numa dinâmica de projeto participativo pressupõe a confiança na (e da) população, oferecendo a ela o espaço nas decisões.

\section{A ETNOGRAFIA APLICADA AO DESIGN}

No design para o desenvolvimento do território a observação em campo é um elemento-chave na construção da competitividade e da sustentabilidade das atividades produtivas locais. Os horizontes da pesquisa do designer se abrem frente as comunidades, mais ou menos, espalhadas sobre um espaço geográfico. Então, o principal objetivo do designer na fase metaprojetual deve ser aquele de coletar, analisar e interpretar as informações diretamente no território. Desse modo, as ferramentas derivadas da etnografia se revelam muito eficazes.

A pesquisa etnográfica é orientada para detectar e identificar os usos, os costumes e as manifestações culturais de uma determinada comunidade. É um processo de produção de conhecimento baseado na observação em campo da vida e das ações sociais de grupos, organizações e comunidades 
através da análise do contexto, da participação nas atividades e na coleta de informações junto aos membros de um grupo. O resultado de uma análise etnográfica é, de fato, uma observação detalhada e ricamente documentada de uma determinada situação.

Para Cautela (2007, p. 89), a pesquisa de tipo etnográfica se divide em três momentos principais: A planificação da pesquisa e a definição do campo no qual são identificados os objetivos, os limites e as ferramentas de pesquisa. A coleta de dados que é conduzida através de técnicas de observação direta das fontes. E a organização e apresentação dos dados colhidos através da documentação e da construção de relações de síntese. Inserindo-se diretamente no campo, o designer consegue delinear as características de uma cultura e de um contexto partindo do ponto de vista das pessoas que ali residem. Ainda segundo Cautela (2007, p. 90) o escopo dessa atividade é aquele de reconstruir o perfil da cultura e do contexto do ponto de vista dos seus membros. Delinear as regras que governam a interação social, pondo em foco os mecanismos de causa que ligam os eventos que o pesquisador assiste. Descrever eventos, ações e situações das quais as pessoas têm pouca consciência a qual atribuir um sentido, um significado, explicar a dinâmica e o curso dos eventos que se sucedem sobre o campo.

O método etnográfico permite focalizar as relações entre o ambiente, as pessoas e os artefatos com o objetivo de compreender, descrever e explicar os rituais, as relações, as criticidades e as convenções nas quais se fundam as ações sociais de grupos, organizações e comunidades para as quais são direcionados os produtos, os serviços e a comunicação. Isso significa não somente que o objeto específico da investigação varia sensivelmente em função da tipologia e da orientação da pesquisa específica que se pretende conduzir, mas, sobretudo que é um objeto sistêmico, um conjunto complexo de relações (CAUTELLA, 2007).

De acordo com Costa (2005, p. 132) o método etnográfico aplicado ao design tem dado origem a uma variante mais concisa da pesquisa etnográfica tradicional, definida por Norman (apud Costa 2005, p. 132) como rapid etnography. Nessa variação, o designer transcorre um certo período de tempo junto ao usuário final para entender os problemas que objetiva afrontar. Enquanto nasce da compreensão da experiência do usuário e da tensão para a melhoria da qualidade de vida, a etnografia rápida suporta a ideação e o desenvolvimento de tipologias de produtos representando, 
portanto, um elemento determinante no contexto da inovação. A principal ferramenta através da qual a etnografia procura alcançar seus objetivos é a observação. Segundo Rizzo (2009, p. 89), como instrumento de design, a etnografia foi utilizada, sobretudo, na forma de observação participativa e sofreu uma série de modificações para fornecer dados úteis ao processo projetual.

Para Rizzo (2009, p. 88), o objetivo da observação participativa em campo é aquele de compreender a natureza e o tipo de atividade que as pessoas executam nos domínios para o qual se está projetando. Isso, permite a identificação das necessidades das pessoas em relação ao seu contexto de vida, explicitando, dessa forma, os requisitos do usuário que poderão ser implementados em um novo produto ou serviço.

De acordo com Cautela (2007, p. 92), o designer, quando se encontra na observação em campo, deve respeitar o principal requisito da pesquisa etnográfica, ou seja, aquele de manter a distância entre si (o pesquisador) e o objeto a ser observado (as pessoas, a comunidade, etc.). Todavia, é igualmente importante tomar parte ativa em um evento ou numa dinâmica interativa para poder compreender, até o fim, as especificidades, a essência e as suas lógicas. Essas duas necessidades, aparentemente contraditórias, são a direta consequência de um dos principais axiomas que guiam a investigação no âmbito das ciências sociais, segundo o qual aquilo que as pessoas dizem que fazem e aquilo que realmente fazem nem sempre coincide.

Para Cautela (2007, p. 93), a observação participativa requer, então, que o pesquisador tenha acesso à comunidade que será investigada e experimente, em primeira pessoa (se possível), o que acontece. A observação pode ser diferentemente dirigida para um acontecimento, um local, sobre uma pessoa ou sobre um objeto.

Segundo Tosi (2006, p. 122) existem três tipos de técnicas de observação participativa. Cada uma requer uma clara definição dos objetivos que se deseja alcançar:

a) Técnicas descritivas, onde o observador registra simplesmente os eventos no momento em que eles acontecem considerando o seu tempo de execução, a frequência e a sequência dos eventos, entre outros;

b) Técnicas de avaliação, onde o observador avalia o resultado ou a consequência dos eventos que aconteceram;

c) Técnicas de diagnóstico, onde o observador identifica as causas que 
deram origem aos eventos.

Para Rizzo (2009, p. 90), a aplicação da observação participativa no design demanda a consideração de uma série de condições. A intenção explícita de estudar as atividades das pessoas nos domínios naturais nos quais acontecem. $O$ interesse para desenvolver descrições detalhadas das experiências observadas. A atenção sobre aquilo que as pessoas estão fazendo em um determinado momento para compreender as relações entre as atividades e o ambiente. Alternar observação e teste tendo a certeza de estar sempre sobre a experiência concreta e concentrar-se nas atividades das pessoas. Ter certeza de não se afastar da atividade concreta e ser indiscreto.

Ainda segundo Rizzo (2009, p. 91), o princípio da interpretação dos dados sugere proceder a essa atividade com o objetivo de construir significado entorno daquilo que foi observado. Transformar os fatos em decisões de design compartilhando as interpretações com os usuários finais. Investigar focalizando a atenção sobre o inesperado significa que é necessário ter presente que o foco da atenção condiciona aquilo que será observado e notado. É necessário observar procurando coletar os elementos de surpresa, as coisas que parecem erradas, as coisas que parecem exatamente como se esperava, compreendendo se a interpretação que se esperava é aquela correta na realidade do contexto observado, as coisas que não se compreendem, a própria ignorância em mérito, colocando perguntas de modo correspondente. É necessário observar não sobre a base das próprias suposições de como o produto ou o serviço deveria ser e funcionar E, finalmente, precisa sempre ter a oportunidade de convidar o usuário final para participar das atividades de construção do significado sobre os dados coletados.

Os dados etnográficos incluem as descrições textuais, os registros em vídeo, storyboards, esboços, imagens e os artefatos gerados das atividades observadas. As principais ferramentas de suporte para a observação participativa de campo são as entrevistas, os questionários, os protocolos verbais e a coleta de histórias.

\section{CONSIDERAÇÕES FINAIS}

O design no processo de desenvolvimento local é uma atividade profundamente ligada ao quotidiano das ações que animam o território. A 
observação participativa e o envolvimento dos atores locais são, portanto, características necessárias para a construção do programa de projeto enquanto permitem a coleta de informações diretamente do contexto e a inserção dos conhecimentos locais no processo criativo do design.

Deste modo, os objetivos e os propósitos do projeto se expandem e o designer pode assumir, também, novos comportamentos como aquele de pesquisador (quando observa o território), de facilitador do processo de co-design, de coordenador das equipes de projeto e de mediador entre as diversas disciplinas e atividades envolvidas na solução dos problemas.

A fase metaprojetual representa o período onde ocorre a análise dos problemas e a investigação de campo, referente à diagnose local e a estruturação dos problemas de projeto. Esta é a fase na qual o designer, através da sua experiência e conhecimento do contexto, pode relacionar os problemas e as necessidades identificadas com as possíveis categorias para a sua solução, ou seja, é um momento propício para a elaboração de mapas com as relações entre as necessidades e os atributos de qualidade mais adequados para atendê-las.

Nestas relações, emergem as formas materiais: produtos, dispositivos, ferramentas, estruturas, entre outros; e as formas imateriais: serviços, comportamentos, estratégias, sistemas, entre outros, que podem ser ativadas através de uma proposital projetação que preencherá as séries de necessidades identificadas. Cada relação pode dar forma, por assim dizer, aos cenários, isto é, às visões de conjunto dos resultados diretos e indiretos que podem ser alcançados com a execução dos projetos.

Assim, cada cenário pode ser estudado em relação a sua viabilidade e classificado em função das prioridades elencadas durante o processo colaborativo de desenvolvimento territorial. Por isso, os cenários podem ser definidos também como visões de um sistema de satisfação e os elementos materiais e imateriais que destes derivam, podem representar os objetivos e requisitos que um design para o território deve perseguir.

\section{BIBLIOGRAFIA}

BONSIEPE, G. Diseño industrial, tecnología e dependencia. México, D.F.: Edicol, 1978.

COLLINA, L. (Org.). Design e metaprogetto. Teorie, strumenti, pratiche. Milão: Poli. 
Design, 2005.

COSTA, F. Valutare I'usabilità: metodi di prova con utenti e tecniche empiriche. In TOSI, F. (Org.). Ergonomia progetto prodotto. Milão: FrancoAngeli, 2005, p. 127154.

DE MORAES, D. Metaprojeto: o design do design. São Paulo: Blucher, 2010.

DESERTI, A. (Org.). Metaprogetto. Riflessioni teoriche ed esperienze didattiche. Milão: Poli.Design, 2003.

OBSERVATÓRIO EUROPEU LEADER. Coinvolgere la popolazione nello sviluppo locale. In L'attuazione del progetto di sviluppo locale: I'esperienza di Leader I, Guida metodologica, parte I, janeiro 1996a.

La diagnosi territoriale e la realizzazione di un progetto di sviluppo. In L'attuazione del progetto di sviluppo locale: I'esperienza di Leader I, Guida metodologica, parte II, gennaio 1996b.

RIZZO, F. Strategie di co-design. Teorie, metodi e strumenti per progettare con gli utenti. Milão: FrancoAngeli, 2009.

TOSI, F. Ergonomia progetto prodotto. Milão: FrancoAngeli-Poli.Design, 2005.

Recebido: 27/11/2015;

Aceito em: 22/04/2016.

Esta obra foi licenciada com uma Licença Creative Commons.
André de Souza Lucca é Bacharel em Desenho Industrial e Doutor em Ciências do Design. Entre 2012 e 2013 realizou Pós-doutorado na UFPR colaborando com a equipe do Núcleo de Design e Sustentabilidade. Atualmente é professor adjunto da UFMA e docente do Mestrado em Design. Efetua pesquisas nas áreas do Design sustentável e do Design para a valorização de produtos, competências e identidades locais. As suas principais publicações são "Considerações metodológicas para a estruturação de uma abordagem projetual coerente com o Design Sustentável", "Valorização dos Recursos Locais: Relações entre os Obstáculos da Cadeia de Produtos do Extrativismo e a Gestão do Design", "Design participativo para a valorização da produção do território" e "Competitividade territorial e inovação sustentável". 